\title{
Sudden death in children and adolescents
}

\author{
C Wren, J J O’Sullivan, C Wright
}

\begin{abstract}
Objective-To identify the incidence, causes, and characteristics of sudden death at age 1-20 years.

Design-A review of all deaths at age 1-20 years. Death certificates were obtained from the Office for National Statistics, and further information, where appropriate, from coroners, paediatricians, physicians, and pathologists.

Setting-The resident population of one English health region in 1985-1994.

Results-In a population of 806500 children and adolescents aged 1-20 years there were 2523 deaths in 10 years. Medical causes accounted for 1017 deaths (40\%); 1236 (49\%) were unnatural, and $270(11 \%)$ were sudden. These sudden deaths comprised 142 with a previous diagnosis, the commonest being epilepsy 49 (34\%), cardiovascular disease $33(23 \%)$, and asthma $30(21 \%)$; 87 attributed to a cause discovered at necropsy, which was respiratory infection in $32(37 \%)$, other infections in $17(20 \%)$, and unsuspected cardiovascular abnormalities in $26(30 \%) ; 41$ remained unexplained.

Conclusions-Half of all sudden deaths in children or adolescents were attributed to an already diagnosed condition. Abnormalities identified at necropsy accounted for one third of sudden deaths. Undiagnosed hypertrophic cardiomyopathy caused less than one death per million person years in the population aged 1-20 years. Unexplained sudden death, which may be caused by primary cardiac arrhythmia, is probably about 10 times more common.

(Heart 2000;83:410-413)
\end{abstract}

Keywords: sudden death; necropsy; paediatric cardiology

Unexpected sudden death is a tragedy at any age but is particularly so in childhood and adolescence. The causes of sudden death in childhood are known but their relative importance is difficult to assess. Population based reports show an age specific rate of sudden unexpected death of 1.3-4.3/year per 100000 population. ${ }^{1-3}$ The variable methods and definitions used and the different eras of these reports make comparisons difficult.

Our aim in this study was to identify the incidence, causes, and characteristics of sudden death, unexpected sudden death and unexplained sudden death in the 1-20 year age group.

\section{Methods}

POPULATION

The population resident in the Northern Health Region of England (the counties of Northumberland, Tyne and Wear, Durham, Cumbria, and Cleveland) comprised the study population. In 1985-1994 the mean population aged 1-20 years was 806000 , and for a 10 year study provided 8.06 million age specific person-years.

Paediatric Cardiology, Freeman Hospital, Newcastle upon Tyne NE7 7DN, UK

C Wren

J J O’Sullivan

Department of Pathology, Royal

Victoria Infirmary,

Newcastle upon Tyne

C Wright

Correspondence to: Dr Wren

Accepted 29 October 1999

DATA SOURCES
Copies of death certificates relating to all deaths between the first and 21st birthday of persons resident in the Northern Health Region in 1985-1994 were obtained from the Office for National Statistics. Details of all sudden deaths (as defined below) were obtained from coroners, hospital pathologists, hospital paediatricians or physicians, and cardiology department records, as appropriate.
No approach was made to family doctors or families.

\section{DEFINITIONS}

The World Health Organization (WHO) definition of sudden death includes instantaneous deaths and all deaths occurring within 24 hours of an acute collapse. ${ }^{4}$ Like other investigators, ${ }^{5-7}$ we found this definition unworkable, as from the records available it was impossible to identify retrospectively some deaths defined in this way. The 24 hour cut off is also arbitrary, as collapse may lead to coma, with a diagnosis of brain death being delayed for more than 24 hours from the initial collapse. ${ }^{6}$ For these reasons we included under the definition of "sudden death" only deaths that occurred suddenly out of hospital, or on arrival at hospital, or in the accident and emergency department. Deaths that occurred after admission to hospital, even within 24 hours from the initial collapse, were excluded.

The cause of death given by the coroner or the coroner's pathologist on the death certificate was accepted as the true cause of death for the purpose of classification, even though in several cases the pathological findings seemed insufficient to account for death. Each death in the 1-20 year age group was classified in one of five categories:
- Unnatural deaths (including homicide, suicide, drowning, poisoning, and all other violent deaths).

- Sudden deaths attributed to known preexisting conditions. 
- Unexpected sudden deaths attributed to a natural cause discovered at necropsy examination.

- Unexpected sudden deaths which remained unexplained after necropsy examination.

ETHICAL APPROVAL

Ethical approval for the project was granted by the joint ethics committee of Newcastle and North Tyneside Health Authority and the University of Newcastle upon Tyne.

\section{Results}

In the 10 years of the study in a population of 3.1 million, there were 385080 deaths, of which $3450(0.9 \%)$ occurred in infancy, 2523 $(0.6 \%)$ at age $1-20$ years, and 379102 $(98.5 \%)$ at age 21 years or older.

Of the 2523 deaths at age 1-20 years which form the basis of this study, 1017 (40\%) were not sudden and were from medical causes, and $1236(49 \%)$ were unnatural. There were 270 (11\%) sudden deaths (3.3/100 000 per year).

Death was attributed to a previously diagnosed condition in $142(53 \%)$ of the 270 sudden deaths (table 1). The commonest causes were epilepsy and asthma. Deaths attributed to "mental retardation" or "cerebral palsy" without mention of epilepsy are recorded separately. Cardiovascular abnormalities were found in $23 \%$ of cases and are listed in table 1 . Two previously asymptomatic children with known aortic valve stenosis died at 13 and 5 years of age with Doppler velocities of 3.0 and $4.2 \mathrm{~m} / \mathrm{s}$, respectively. None of the six children with atrial repair of transposition of the great arteries had any previous atrial arrhythmia. One patient with repaired tetralogy of Fallot had poor ventricular function and the other had good cardiac function and a permanent ventricular pacemaker for postoperative complete atrioventricular block. Neither child with complete atrioventricular block and unrepaired congenital heart disease had a pacemaker, although retrospective review showed both had average ventricular rates below $50 / \mathrm{min}$ on Holter monitoring.

In 87 cases $(32 \%)$, sudden death was attributed to an abnormality first discovered at necropsy (table 2). Thirty two deaths (37\%)

Table 1 Causes of sudden deaths attributed to previous diagnoses

\begin{tabular}{lc}
\hline Epilepsy & $49(34 \%)$ \\
Asthma & $30(21 \%)$ \\
Cerebral palsy & $19(13 \%)$ \\
Cardiovascular & $33(23 \%)$ \\
Pulmonary atresia & 7 \\
Transposition of great arteries & $6^{\star}$ \\
Pulmonary vascular disease & $5 \dagger$ \\
Dilated cardiomyopathy & 4 \\
Aortic valve stenosis & 2 \\
Tetralogy of Fallot & $2^{\star}$ \\
Congenital atrioventricular block & $2 \dagger$ \\
Congenital long QT syndrome & 1 \\
Other & 4 \\
Miscellaneous $\ddagger$ & $11(8 \%)$ \\
Total & $142(100 \%)$
\end{tabular}

*Postoperative.

+With congenital heart disease

$¥$ Miscellaneous causes of death were obstructed tracheostomy (2), pulmonary embolism (2), hydrocephalus (3), chronic renal failure (1), bronchopulmonary dysplasia (1), lupus myocarditis (1), and diabetes mellitus (1).
Table 2 Causes of sudden deaths attributed to an abnormality discovered at necropsy

\begin{tabular}{ll}
\hline Respiratory infection & $32(37 \%)$ \\
Other infections & $17(20 \%)$ \\
Cardiovascular abnormalities & $26(29 \%)$ \\
Aortic valve stenosis & 7 \\
Hypertrophic cardiomyopathy & 6 \\
Myocarditis & 5 \\
Coronary artery abnormality & 3 \\
$\quad$ Myocardial infarction with coronary atheroma & 1 \\
Kawasaki disease & 1 \\
Anomalous origin of the left coronary artery & \\
$\quad$ from the main pulmonary artery & 1 \\
Coarctation & 2 \\
Other cardiomyopathy & 2 \\
Myocardial angioma & 1 \\
Miscellaneous & $12(14 \%)$ \\
Total & $87(100 \%)$
\end{tabular}

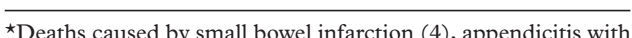
peritonitis (2), pulmonary embolus (4), subarachnoid haemorrhage (1), and acute hydrocephalus (1).

were attributed to respiratory infections, which varied from fulminant bronchopneumonia or lobar pneumonia to "tracheobronchitis." In some of these last cases, retrospective reading of the coroner's pathologist's report led to doubts that the findings were sufficient to account for death. Other infections (for example, meningitis, epiglottitis) caused 17 deaths $(20 \%)$. Cardiovascular abnormalities accounted for 26 deaths (30\%), and the causes are shown in table 2 . In none of the cases of hypertrophic cardiomyopathy was there any evidence of a family history of that disease, but the data were not complete.

The cause of sudden unexpected death remained unknown after necropsy examination in 41 cases ( $15 \%$ of all sudden deaths). Twenty of these were younger than two years at the time of death, which often occurred during sleep and was not discovered until the morning. Of 21 cases who were older than two years at the time of death, 16 were over 11 years of age. In two cases a retrospective diagnosis of congenital long QT syndrome was made, one from a previous ECG and one from a sibling's ECG. The activity at the time of death was known in 15 cases. Three died during sleep and 12 while awake-10 during exercise (ranging from walking to competitive sports) and two at rest.

\section{Discussion}

Our study showed that $11 \%$ of all deaths in childhood and adolescence are sudden, an age specific incidence of 1 in 29000 , or 3.3/ 100000 per year. This is probably an underestimate as we have used a more restrictive definition of sudden death than that of the WHO. ${ }^{4}$ Some deaths that occurred after admission to hospital but within 24 hours, and others which were delayed until after the diagnosis of brain death, are likely to have a similar cause to deaths that occurred out of hospital or on arrival at hospital. ${ }^{56}$

Half of all sudden deaths were attributed to previously diagnosed conditions. The commonest of these were cardiovascular abnormalities, asthma, and epilepsy. Advances in surgical treatment have changed the profile of sudden death in patients with known congenital heart disease. ${ }^{589}$ In our series most such patients 
who died suddenly had undergone palliative or corrective surgery, whereas in the previous era most deaths affected patients with unoperated heart disease. ${ }^{9} 10$

There were no deaths in patients with known hypertrophic cardiomyopathy in our study. This supports suggestions that the sudden death risk in the population is lower than might be supposed from selected reports from specialised centres. ${ }^{71112}$ No patients from the same population with a diagnosis in life of hypertrophic cardiomyopathy had undergone cardiac transplantation or received an implantable defibrillator.

Sudden death from asthma is rare, affecting $1 / 10000$ asthmatic children. ${ }^{13}$ The problem has received much attention over the years but despite extensive investigations and increased knowledge of the mechanisms and pathology, such deaths continue to occur. ${ }^{14}{ }^{15}$ Most deaths in asthma affect those with a history of severe and poorly controlled disease but in $10-20 \%$ of cases death is sudden and unexpected. ${ }^{16}$ In most cases death results from hypoxia rather than cardiac arrhythmia, but the mechanism in those with sudden onset of airway closure is not well understood. ${ }^{15}$

Sudden deaths account for about $10 \%$ of all deaths in patients with epilepsy ${ }^{17}$ and are more common in those with severe epilepsy, poor control, and poor compliance with anticonvulsant drugs. ${ }^{18}{ }^{19}$ Several mechanisms have been proposed, including hypoxia and apnoea secondary to seizures, ${ }^{20}$ death related to drug treatment or drug withdrawal, and cardiac arrhythmias. ${ }^{21}$ In some cases the diagnosis of epilepsy may be wrong. It is well recognised that primary cardiac arrhythmias may produce syncope and anoxic seizures and lead to an incorrect diagnosis of epilepsy. ${ }^{22}$

One third of sudden deaths in our study were attributed to a cause discovered at necropsy examination. Abnormalities producing left ventricular outflow obstruction-aortic valve stenosis, coarctation of the aorta, and hypertrophic cardiomyopathy - were the commonest cardiovascular malformations. Previous reports have highlighted the fact that hypertrophic cardiomyopathy remains the commonest individual structural abnormality discovered at necropsy examination after sudden death in young persons. ${ }^{12}{ }^{23}$ Although such deaths cause much distress, in population terms they are rare. This study identified six deaths from undiagnosed hypertrophic cardiomyopathy in over eight million person years in the 1-20 year age group, an age specific incidence of 1 in 1.35 million, or 0.74 per $10^{6}$ person-years (95\% confidence interval (CI) 0.15 to 1.3 ). This is in keeping with national mortality statistics that show a total mortality from hypertrophic cardiomyopathy in England and Wales in 1988-1992 of six cases a year in a population of 13.5 million aged 1-19 years, an age specific incidence of 1 in 2.25 million, or 0.45 per $10^{6}$ person-years (95\% CI 0.09 to 0.80$).^{24} \mathrm{~A}$ recent report from Finland found 15 deaths from previously undiagnosed cardiomyopathy in 16 million person years at age $0-20$ years $(0.94$ per $10^{6} ; 95 \%$ CI 0.46 to 1.4 ) but it included both hypertrophic and dilated cardiomyopathy. ${ }^{25}$ Although these last two reports consider slightly broader diagnostic groups, they support the suggestion that the annual population risk of sudden death from undiagnosed hypertrophic cardiomyopathy in children and adolescents is less than one in a million. The need to consider the implications for other family members is well known $^{26}$ but there is no convincing evidence that population screening is justified. ${ }^{27} 28$

In this study we have had to accept the coroner's or pathologist's decision about the cause of death even though this is sometimes unconvincing in retrospect. The main responsibility of the coroner's pathologist is to advise whether or not death was from natural causes or was unnatural. ${ }^{29}{ }^{30}$ In infancy it is common to find no cause and death may then be attributed to sudden infant death syndrome. ${ }^{29}$ Beyond infancy death with no cause is less well recognised and any pathological findings at necropsy may, rightly or wrongly, be taken to be the cause of death. If this assigns cases correctly to natural or unnatural causes then in legal terms this is not an inappropriate decision, but it can be difficult to be sure from the death certificate whether the documented abnormality was sufficient to be the true cause of death. We believe that in at least some of the deaths attributed to respiratory infections or epilepsy there may really have been no identified cause of death at post mortem examination.

Fifteen per cent of sudden deaths remained unexplained after necropsy examination. Half of these occurred at less than two years of age and they had similar characteristics to sudden unexpected death in infancy in that victims were usually found dead in bed in the morning. The profile of deaths occurring beyond two years of age may give some clue to the underlying causes: 16 of $21(76 \%)$ were older than 11 years at the time of death, and in 10 of 15 $(67 \%)$ for whom data on activity at time of death were available, death was related to exertion. This profile is compatible with several diagnoses known to carry a risk of sudden death but which would leave no clue at necropsy. They include congenital long QT syndrome, ${ }^{31}$ idiopathic ventricular arrhythmias, ${ }^{32} 33$ Wolff-Parkinson-White syndrome, ${ }^{34}$ congenital complete atrioventricular block, ${ }^{35}$ and hypertrophic cardiomyopathy with minimal phenotypic expression, such as in troponin T mutations. ${ }^{36}$ The prevalence of each of these conditions in a population is impossible to determine. Although congenital long QT syndrome and hypertrophic cardiomyopathy are sometimes recognised as familial conditions, many cases are apparently sporadic. Such cases may result from either low phenotypic penetrance or from new mutations. ${ }^{37}$ Both have a dominant inheritance and a high risk of sudden death and therefore new mutations would be expected to predominate in the population, so the lack of a positive family history would not be surprising. It is probable that most or all cases of long QT syndrome and hypertrophic cardiomyopathy have an underlying genetic 
abnormality. It is possible, therefore, that saving blood or tissue samples after unexplained sudden death might eventually allow retrospective attribution of a precise cause of death.

Population based data, such as those reported in this study, may stimulate and inform discussion on screening which has been proposed for abnormalities such as hypertrophic cardiomyopathy and congenital long QT syndrome. ${ }^{27} 2838$ Wider recognition and acceptance by the medical and legal professions that some sudden deaths in children or adolescents cannot be explained by present knowledge (similar to the diagnosis of sudden infant death syndrome in infancy) may lead to more accurate recognition of victims and may stimulate research into potential underlying causes.

We are indebted to the Northern and Yorkshire National Health Service Research and Development Programme for financial support, to the Office for National Statistics for providing data on all deaths, and to Professor P Pharoah for reviewing the manuscript. We are also grateful to the following for providing manuscript. We are also grateful to the following for providing Gxtra information on individual cases: Coroners-O J Bjorkeroth, G N Burt, R M Butler, L Coyle, W Duffy, C B Gallon, M S Howells, W R Knowles, I G McCreath, C Moore, I H Morton, I Smith, J C Taylor. Archivists-E A Rees, J Gill. I Smith, J C Taylor., Archivists - E A Rees, J Gill.
Paediatricians - A Cotterell, R Dias, S Hodges, W Houlsby, J C Jani, A P Kenna, H J Lambert, G R Lawson, M F Lowry, M Massam, M Oo, V Ramesh, N Speight, C Stuart, D N Symon, $M$ Taylor, I M Thakur, I G Verber, U Wariyar, J P Wyllie. Physicians and pathologists-P M Earnshaw, K L Evemy, J P Sunter, B C Thwaites, A J Wright.

1 Molander N. Sudden natural death in later childhood and adolescence. Arch Dis Child 1982;57:572-6.

2 Driscoll DJ, Edwards WD. Sudden unexpected death in children and adolescents. F Am Coll Cardiol 1985;5:118$21 \mathrm{~B}$.

3 Neuspiel DR, Kuller LH. Sudden and unexpected natural death in childhood and adolescence. FAMA 1985;254: 1321-5.

4 Roberts WC. Sudden cardiac death: definitions and causes. Am $\mathcal{F}$ Cardiol 1986;57:1410-13.

5 Silka MJ, Hardy BG, Menashe VD, et al. A populationbased prospective evaluation of risk of sudden cardiac based prospective evaluation of risk of sudden cardiac death after operation for commo

6 Epstein AE, Carlson MD, Fogoros RN, et al. Classification of death in antiarrhythmic drug trials. $\mathcal{F} \mathrm{Am}$ Coll Cardio 1996;27:433-42.

7 Corrado D, Basso C, Schiavon M, et al. Screening for hypertrophic cardiomyopathy in young athletes. $N$ Engl $f$ Med 1998;339:364-9.

8 Wren C. Late postoperative arrhythmias. In: Wren C, Campbell RWFC, eds. Paediatric cardiac arrhythmias. Oxford: Oxford University Press, 1996:238-59.

9 Lambert EC, Menon VA, Wagner HR, et al. Sudden unexpected death from cardiovascular disease in children. $A m \mathcal{F}$ Cardiol 1974;34:89-96.

10 Garson A, McNamara DG. Sudden death in a paediatric cardiology population, 1958 to 1983: relation to prior arrhythmias. $¥$ Am Coll Cardiol 1985;5:134-7B.
11 Liberthson RR. Sudden death from cardiac causes in children and young adults. N Engl f Med 1996;334:103944.

12 Spirito P, Seidman CE, McKenna WJ, et al. The management of hypertrophic cardiomyopathy. $N$ Engl $\mathcal{F}$ Med 1997;336:775-85.

13 Champ CS, Byard RW. Sudden death in asthma in childhood. Forensic Sci 1994;66:117-27.

14 Kay AB. Pathology of mild, severe, and fatal asthma. Am $\mathcal{F}$ Respir Crit Care Med 1996;154:S66-9.

15 Strunk RC. Death due to asthma. Am Rev Respir Dis 1993; 148:550-2.

16 Gibson GJ. Perception, personality and respiratory control in life threatening asthma. Thorax 1995;50(suppl 1):S2-4.

17 Earnest MP, Thomas GE, Eden RA, et al. The sudden unexplained death syndrome in epilepsy: demographic, clinical and postmortem features. Epilepsia 1992;33:31016.

18 Tennis P, Cole TB, Annegers JF, et al. Cohort study of incidence of sudden unexplained death in persons with seizure disorder treated with antiepileptic drugs in Saskatchewan, Canada. Epilepsia 1996;36:29-36.

19 Nashef L, Sander JW. Sudden unexpected deaths in epilepsy-where are we now? Seizure 1996;5:235-8.

20 Nashef L, Walker F, Allen P, et al. Apnoea and bradycardia during epileptic seizures: relation to sudden death in epilepsy. ₹ Neurol Neurosurg Psychiatry 1996;60:297-300.

21 Tubridy N, Redmond JMT. Sudden unexpected death in epilepsy. Irish Med f 1996;89:212.

22 Linzer M, Grubb BP, Ho S, et al. Cardiovascular causes of oss of consciousness in patients with presumed epilepsy: a cause of the increased sudden death rate in people with epilepsy? Am F Med 1994;96:146-54.

23 Maron BJ, Shirani J, Poliac LC, et al. Sudden death in young competitive athletes. FAMA 1996;276:199-204.

24 Office of Population Censuses and Surveys. Mortality statistics. DH Nos 15-19. London: HMSO, 1988-1992.

25 Arola A, Jokinen E, Ruuskanen O, et al. Epidemiology of diopathic cardiomyopathies in children and adolescents. A nationwide study in Finland. Am f Epidemiol 1997;146: 385-93.

26 Goodwin JF. Sudden cardiac death in the young. BMF 1997;314:843.

27 Clark AL, Coats AJS. Screening for hypertrophic cardiomyopathy. BMF 1993;306:409-10

28 Fananapazir L, Epstein ND. Prevalence of hypertrophic cardiomyopathy and limitations of screening methods. Circulation 1995;92:700-4.

29 Vujanic GM, Cartlidge PHT, Stewart JH, et al. Perinatal and infant post mortem examinations: how well are we doing? f Clin Pathol 1995;48:998-1001.

30 Chen K. The coroner's necropsy - an epidemiological treasure trove. F Clin Pathol 1996;49:689-99.

31 Garson A, Dick M, Fournier A, et al. The long QT syndrome children. An international study of 287 patients. Circulation 1993;87:1866-72.

32 Leenhardt A, Lucet V, Denjoy I, et al. Catecholaminergic polymorphic ventricular tachycardia in children. Circulation 1995;91:1512-19.

33 Brugada J, Brugada R, Brugada P. Right bundle branch block and ST-segment elevation in leads $V_{1}$ through $V_{3}$. A marker for sudden death in patients without demonstrable structural heart disease. Circulation 1998;97:457-60.

34 Timmermans C, Smeets JL, Rodriguez LM, et al. Aborted sudden death in the Wolff-Parkinson-White syndrome. Am f Cardiol 1995;115:492-4.

35 Ross BA. Congenital complete atrioventricular block. Pediatr Clin North Am 1990;37:67-78.

36 Moolman JC, Corfield VA, Posen B, et al. Sudden death due to troponin T mutations. F Am Coll Cardiol 1997;29:54955.

37 Priori SG, Napolitano C, Schwartz PJ. Low penetrance in the long QT syndrome. Circulation 1999;99:529-33.

38 Ino $\mathrm{T}$, Yabuta $\mathrm{K}$, Yamauchi $\mathrm{K}$. Heart disease screening in Japanese children. BMF 1993;306:1128. 